Reference: Biol. Bull., 153: 145-162. (August, 1977)

\title{
COCKROACH MOLTING. II. THE NATURE OF REGENERATION- INDUCED DELAY OF MOLTING HORMONE SECRETION
}

\author{
JOSEPH G. KUNKEL
}

Department of Zoology, University of Massachusetts at Amherst, Amherst, Massachusetts 01003

The study of intrinsic controls of growth and development in organisms has often been aided by the availability of extrinsic cues which permit the organism to be manipulated or stimulated in a close to normal fashion by the experimenter from the periphery. Regeneration of autotomized or lost parts in arthropods is just such a convenient process, often allowing manipulation of the developmental program of the animals. Loss of scales in firebrats (Rohdendorf and Watson, 1969; Larink, 1975) and legs in crustaceans (Holland and Skinner, 1976) result in precocious molting. Excision of wing discs of Ephestia (Pohley, 1965) or autotomy of cockroach legs (O'Farrell and Stock, 1953, 1954; Stock and O'Farrell, 1954; Bulliere, 1967, 1968a, b; Kunkel, 1975a) result in a delay of the molting process in order to regenerate the lost limb. In some groups of arthropods there is apparently no modification of the molting cycle to accommodate regeneration (Luscher, 1958; Shaw and Bryant, 1974). Unraveling the mystery of how regeneration modifies the molting cycle in various groups will hopefully result in a deeper appreciation of how the arthropod molting cycle is controlled in general.

Attempts have been made to learn how the endocrine events of the cockroach molting cycle interact with the regenerating limb (Penzlin, 1965). Although progress has been made in understanding the means by which the ecdysone can inhibit and perhaps terminate the molting delay (Bulliere, Bulliere and Sengal, 1969; Bulliere and Bulliere, 1970; Marks, 1973; Kunkel, 1975b), there is as yet no concensus as to how the delay of the molting phase is initially established. While earlier experiments suggest that regenerating tissue metabolizes the molting hormone, ecdysone, and as a result prevents molt initiation (O'Farrell, Stock, Rae and Morgen, 1960; Pohley, 1961), the present study reinforces the suggestion (Kunkel, 1975a) that autotomy of a leg inhibits, via a nervous feedback, the release of the brain hormone, ecdysiotropin, needed to initiate a molting cycle.

Although previous reports (Brindley, 1897; O'Farrell et al., 1960; Pohley, 1965; Bulliere, 1968a) of positive correlations between amount of amputated or regenerated tissue and amount of molting delay are undoubtedly correct, these correlations, in the case of the cockroach at least, have been misinterpreted. Inferences have been made that the amount of regenerating tissue causes the length of the molting delay. It has been hypothesized (O'Farrell et al., 1960; Pohley, 1965) that the greater the amount of regenerating tissue, the n-lore ecdysone is metabolized and the longer the delay; this will be referred to as the "injury metabolism model" of molting delay.

Another model, the "nervous-feedback model," proposed in this study, involves a nervous feedback from the ganglion of regenerating limbs to the brain, preventing the release of ecdysiotropin and its subsequent induction of the ecdysone pattern controlling molting. 


\section{MATERIALS AND METHODS}

Six species of cockroach were used in this study: two from the family Blattellidae, Blattella gernianica and Symploce capitata; two from the family Blattidae, Blatta orientalis and Periplaneta americana; and two from the family Blaberidae, Byrsotria fumigata and Leucophaea maderae. Cultures of each species were maintained synchronously at $30^{\circ} \mathrm{C}$ by controlling their food supply (Kunkel, 1966) and by storing them between molting cycles at $15^{\circ} \mathrm{C}$. A strain of $B$. germanica was developed for the purpose of making precise measurements of difference in molting cycle length due to different treatments.

This strain was maintained 50\% heterozygous orange body (+/or) and 50\% homozygous orange body (or/or) (Ross and Cochran, 1966). The heterozygote and the homozygous recessive larvae were distinctly different in body color and could be separated by superficial inspection. The alleles were found to have no differential effect on the length of the molting cycle. This allowed raising genetically labeled control and experimental groups in the same culture dish, eliminating any between-dish effects on developmental rates.

Autotomy of limbs, nerve section experiments, serum sampling and ecdysterone injection were each performed under brief, light $\mathrm{CO}_{2}$ anesthesia. Such anesthesia was tested and found to have no measurable effect on the molting cycle length.

A radioimmune assay for ecdysone in insect serum was developed using antiecdysone (gift of Dr. John D. O'Connor, University of California, Los Angeles) and $3 \mathrm{H}$-ecdysterone (New England Nuclear, $6 \mathrm{Ci} / \mathrm{mmole}$ ). The assay was modified from Borst and O'Connor (1974) and Tyler, Hennan, Newton and Collins (1973). Unknown or standard amounts of cold ecdysone were dried down in $0.4 \mathrm{ml}$ polyethylene vials (Thomas) and $6000 \mathrm{dpm}$ or ${ }^{3} \mathrm{H}$-ecdysone were added in $100 \mu \mathrm{l}$ of Borate buffer $(0.087 \mathrm{~N}$ Borate, $\mathrm{pH} 8.4 ; 0.075 \mathrm{~N} \mathrm{NaCl}$ ). This solution was mixed to suspend and mix the cold and hot ecdysones. To this mixture $100 \mu \mathrm{l}$ of $3 \%$ anti-ecdysone plus $37 \%$ normal rabbit serum in Borate buffer were added and the mixture incubated for 20 minutes at $37^{\circ} \mathrm{C}$, followed by chilling for one hour at $4^{\circ} \mathrm{C}$. To the tubes $200 \mu \mathrm{l}$ of saturated ammonium sulfate was added to precipitate $\gamma$-globulin and bound ecdysone, the tubes were mixed and after 15 minutes centrifuged in a Beckman microfuge for one minute. The unbound and unprecipitated ${ }^{3} \mathrm{H}$-ecdysterone in the supernatant was counted: one hundred ul of supernatant $+1.1 \mathrm{ml}$ of water $+10 \mathrm{ml}$ of Triton-X-100 toluene scintillator (Benson, 1966) were counted in a Beckman Scintillation Spectrometer at a tritium counting efficiency of 50\%. Control 1 (CPM1) consists of the former complete mixture minus any cold ecdysone to establish the maximum antibody precipitable radioactive ecdysone. Control 2 (CPM2) consists of the complete mixture, minus any cold ecdysone, with the $3 \%$ anti-ecdysone replaced with additional amounts of $3 \%$ control rabbit serum, to establish the level of nonspecific binding and precipitation. A standard curve of ecdysone bound (CPMX-CPM1)/(CPM2-CPM1) versus log, cold ecdysone concentration was plotted on probability paper and invariabily gave a straight line. Transformation of percentages to probits allowed linear regression to be performed, and unknown ecdysone values were then computed directly from the regression equation.

Samples for assay of ecdysone were obtained by extraction of $1 / 20$ diluted whole hemolymph with an equal volume of methanol (Bollenbacher, Vedeckis, Gilbert and 


\section{AUTOTOMY_INDUCED MOLTING DELAY}

O'Connor, 1975). The precipitated proteins were removed by centrifugation and the supernatant dried down in vacuo at $45^{\circ} \mathrm{C}$.

\section{RESULTS}

\section{Correlation of degree of injury with delay length}

The injury-metabolism model predicts that the length of molting delay is proportional to the size of the eventual regenerate. This correlation can be observed on a number of levels. The most obvious level, in which different anatomical structures are amputated, gives the most dramatic results. Thus the average delay caused by regeneration at $30^{\circ} \mathrm{C}$ of a femur-tibia-tarsus of fourth instar B. germanica larvae is 55 hours, while regeneration of only the tarsus causes a 25 hour delay of molting. On a more subtle level the molting delay associated with regeneration of a particular anatomical structure can vary considerably; the size of the regenerated structure is proportional to the time the structure had available for regeneration. This phenomenon is illustrated in Figure 1. The observed result that delay is a third degree polynomial of regenerate length, suggests that delay is correlated with the volume of tissue regenerated or to be regenerated.

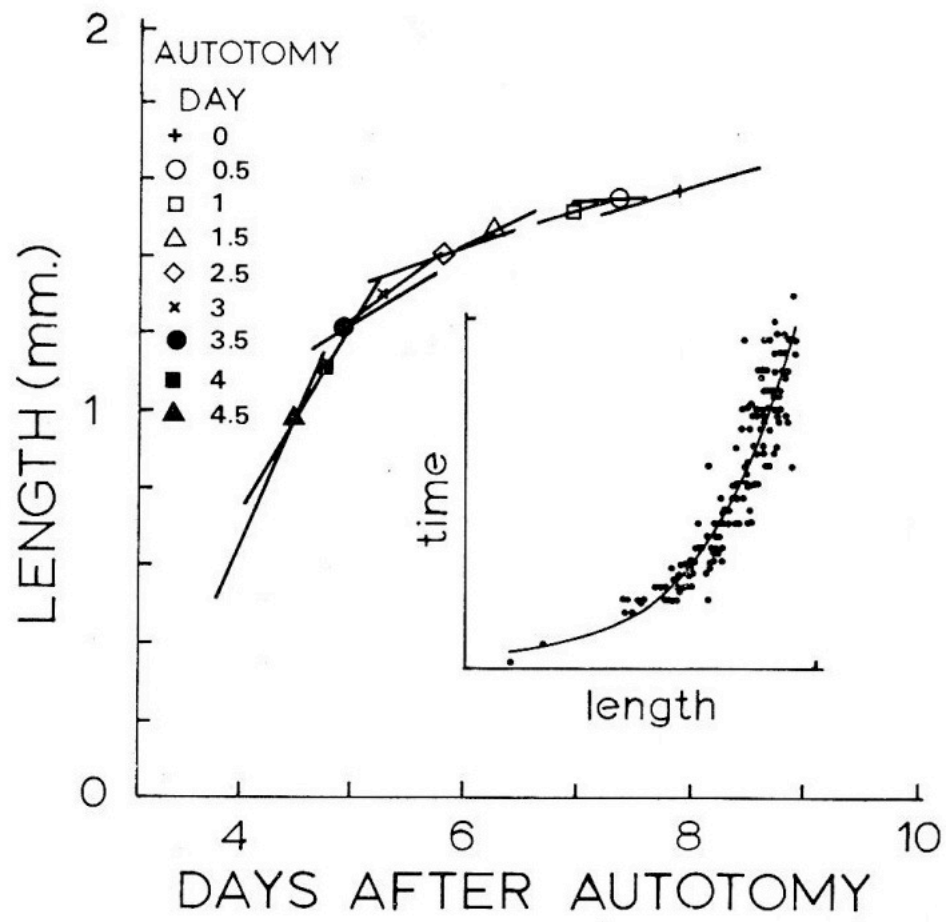

FIGURE 1. Regenerate size as a function of time from autotomy to ecdysis. Each of nine groups of 25 sixth instar $B$. germanica male nymphs had a tarsus autotomized on the specified day after feeding. For each group linear regression was performed on the length of the regenerated first tarsal segment vs. the time from autotomy to ecdysis. The regression line for each group is plotted intersecting the mean regenerate size and ecdysis time for that group and spans the range of molting times in its group. Each regression line has a nonzero $(\mathrm{P}<0.05)$ positive slope. The inset figure shows a third degree polynomial of length fitted to the times from autotomy to ecdysis. 
To test the causal relationship between amount of tissue and amount of delay, a series of experiments were designed to see if delay length could be uncoupled from the amount of tissue regenerating. In the first experiment a culture of 240 third instar larvae of the specially developed strain of $B$. germanica were used; 120 heterozygous (+/or) larvae had their left metathoracic femur-tibia-tarsus autotomized and 120 homozygous recessive (or/or) larvae had their right femur-tibia-tarsus autotomized at 40 hours after feeding. This provided after subsequent regeneration and molting two mirror equivalent groups of fourth instar larvae: +or larvae with small left legs but normal right legs and or/or larvae with normal left legs but small right legs. These fourth instar animals were fed, and 40 hours later either a small or a large metathoracic tarsus was autotomized. The animals were then observed at four hour intervals, and the time of ecdysis and length of the regenerated first tarsal segment was recorded. The sizes of the regenerates of the small vs. large tarsal amputees were highly significantly different $(\mathrm{P}<0.0001)$ and should have resulted in a substantially different delay if regenerate size was causally related to delay length. However, no such delay difference could be detected between the two regenerate groups $(\mathrm{P}>0.10)$. This result suggests that the length of molting delay is associated with some intrinsic property of the thoracic segment and level of autotomy rather than with the size of the amputated part or the size of the regenerate.

A second experiment designed to answer the same question was based on the fact that autotomy of a second leg causes a measurable extra delay when autotomized simultaneously with the first autotomy (Stock and O'Farrell, 1954). In this experiment 832 fourth instar B. germanica larvae were split into two groups of 416 , At 40 hours after feeding, in one group of 416 either one or two tarsi were autotomized. In the other group of 416 one or two femur tibia-tarsi were autotomized.

As in the previous experiment, the time of ecdysis was recorded for each animal in the four treatment groups. Although there was a highly significant 26 hour difference between the delay caused by autotomy at the level of the tarsus versus autotomy of the femur-tibia-tarsus $(\mathrm{P}<0.0001)$, and there was a highly significant five hour difference between whether one or two limbs were autotomized in single animals $(\mathrm{P}<0.0001)$, there was no significant difference $(\mathrm{P}>0.75)$ in the delay caused by a second tarsus as compared to a second femur-tibia-tarsus. Both of these experiments suggest that the bulk of the regenerating tissue has no role in controlling the length of the delay of molting.

\section{Uniformity of delay associated with regeneration}

A length-of-delay of molting is associated with each thoracic segment (metathorax $>$ mesothorax $>$ prothorax) and autotomy level (tarsal $<$ femur-tibia-tarsal). This uniform delay for each autotomy type is demonstrated when one measures the synchrony of ecdysis in leg regenerating cockroaches and compares this synchrony to the degree of synchrony achieved simply by controlling feeding. Table I lists for six species of cockroach the mean time of ecdysis and the variance of ecdysis in cultures synchronized by feeding, compared to equivalent groups of animals which, in addition, had a metathoracic femur-tibia-tarsus autotomized at the indicated times. Different autotomy times were necessary due to the varying length of the different species molting cycles. In each species, forcing animals to regenerate a limb improves the synchrony of the 


\section{AUTOTOMY_INDUCED MOLTING DELAY}

TABLE I

Limb autotomy induced reduction in the variance, $V=(t-t) 2 / n-1$, of molting time, $t$, in feedingsynchronized cockroach cultures. Multiple parallel cultures of Blattella germanica and Periplaneta americana demonstrate the uniformity of variance reduction. Pooled variances for unautotomized (-) and for autotomized $(+)$ cultures were obtained where appropriate prior to calculating the variance ratio, $F$, testing equality of variance. The probability $(P)$ that such a reduction in variability could have occurred by chance is tabulated. Time is measured in hours from initial food availability.

\begin{tabular}{|c|c|c|c|c|c|c|c|c|}
\hline \multirow{2}{*}{ Species } & \multirow{2}{*}{ Instar } & \multirow{2}{*}{ Culture } & \multicolumn{2}{|c|}{ Autotomy } & \multirow{2}{*}{$\begin{array}{l}\text { Culture } \\
\text { size, } \\
\text { n }\end{array}$} & \multirow{2}{*}{$\begin{array}{c}\text { Mean } \\
\text { molting } \\
\text { time, } \\
t\end{array}$} & \multirow{2}{*}{$\mathrm{V}$} & \multirow{2}{*}{$\begin{array}{l}\mathrm{F} \\
(P)\end{array}$} \\
\hline & & & $+1-$ & time & & & & \\
\hline \multirow[t]{2}{*}{$\begin{array}{l}\text { Blatella } \\
\quad \text { germanica }\end{array}$} & \multirow[t]{2}{*}{ IV } & $\begin{array}{l}\text { A } \\
B \\
C \\
D \\
E \\
F \\
G \\
H\end{array}$ & $\begin{array}{l}- \\
- \\
- \\
- \\
- \\
- \\
- \\
-\end{array}$ & & $\begin{array}{l}132 \\
139 \\
133 \\
151 \\
125 \\
137 \\
141 \\
154\end{array}$ & $\begin{array}{l}153 \\
147 \\
155 \\
157 \\
161 \\
158 \\
158 \\
154\end{array}$ & $\begin{array}{l}297 \\
184 \\
248 \\
260 \\
243 \\
159 \\
264 \\
181\end{array}$ & \multirow{2}{*}{$\begin{array}{c}2.86 \\
(<0.0001)\end{array}$} \\
\hline & & $\begin{array}{l}\mathrm{I} \\
\mathrm{J} \\
\mathrm{K} \\
\mathrm{L}\end{array}$ & $\begin{array}{l}+ \\
+ \\
+ \\
+\end{array}$ & $\begin{array}{l}40 \\
40 \\
40 \\
40\end{array}$ & $\begin{array}{l}139 \\
121 \\
125 \\
132\end{array}$ & $\begin{array}{l}212 \\
206 \\
202 \\
198\end{array}$ & $\begin{array}{l}82 \\
90 \\
59 \\
88\end{array}$ & \\
\hline \multirow[t]{2}{*}{$\begin{array}{l}\text { Periplaneta } \\
\text { americana }\end{array}$} & \multirow[t]{2}{*}{ VII } & $\begin{array}{l}\mathrm{A} \\
\mathrm{B}\end{array}$ & - & & $\begin{array}{l}61 \\
44\end{array}$ & $\begin{array}{l}181 \\
215\end{array}$ & $\begin{array}{l}121 \\
123\end{array}$ & \multirow{2}{*}{$\begin{array}{c}1.492 \\
(<0.025)\end{array}$} \\
\hline & & $\begin{array}{l}\mathrm{C} \\
\mathrm{D}\end{array}$ & $\begin{array}{l}+ \\
+\end{array}$ & $\begin{array}{l}48 \\
48\end{array}$ & $\begin{array}{l}51 \\
60\end{array}$ & $\begin{array}{l}296 \\
308\end{array}$ & $\begin{array}{l}81 \\
82\end{array}$ & \\
\hline \multirow{2}{*}{$\begin{array}{l}\text { Blatta } \\
\quad \text { orientalis }\end{array}$} & \multirow[t]{2}{*}{$\mathrm{V}$} & $\mathrm{A}$ & - & & 292 & 211 & 334 & \multirow{2}{*}{$\begin{array}{r}1.406 \\
(<0.05)\end{array}$} \\
\hline & & B & + & 96 & 71 & 359 & 237 & \\
\hline \multirow{2}{*}{$\begin{array}{l}\text { Symploce } \\
\text { capitata }\end{array}$} & \multirow[t]{2}{*}{ V } & A & - & & 165 & 244 & 1024 & \multirow{2}{*}{$\begin{array}{c}2.32 \\
(<0.0001)\end{array}$} \\
\hline & & B & + & 96 & 215 & 345 & 441 & \\
\hline \multirow{2}{*}{$\begin{array}{l}\text { Byrsotria } \\
\text { fumigata }\end{array}$} & \multirow[t]{2}{*}{ IV } & $\mathrm{A}$ & - & & 34 & 443 & 3963 & \multirow{2}{*}{$\begin{array}{c}7.28 \\
(<0.0001)\end{array}$} \\
\hline & & $\mathrm{B}$ & + & 120 & 27 & 496 & 544 & \\
\hline \multirow{2}{*}{$\begin{array}{l}\text { Leucophaea } \\
\text { maderae }\end{array}$} & \multirow[t]{2}{*}{$\mathrm{V}$} & $\mathrm{A}$ & - & & 150 & 324 & 1431 & \multirow{2}{*}{$\begin{array}{c}2.62 \\
(<0.0001)\end{array}$} \\
\hline & & B & + & 163 & 139 & 528 & 546 & \\
\hline
\end{tabular}

eventual ecdysis. This suggests that there is a relatively precise delay programmed for each type of regenerating leg. When the delay is over, all the animals are ready to molt as if they had been queued up at a gate.

\section{Independent feedback of regenerating limbs}

In addition to the added synchrony caused when one leg is autotomized, if two metathoracic legs are autotomized at the same time in each animal, a substantially 
significant additional synchrony is achieved. This is demonstrated for two species of cockroaches in Table II. This additional synchrony due to a second autotomized limb can adequately be accounted for if it is assumed that the two feedbacks of the two regenerating limbs on the control of molting are independent of each other. In that situation, due to the laws of statistical independence, the probability of the second of two independent limbs stopping its inhibition of molting at a given time is simply the square of the probability of a single limb stopping its feedback by that time. This hypothesis is tested in an additional experiment illustrated in Fig 2. According to the independent feedback hypothesis, the cumulative molting curve for the double autotomy animals should be predicted by simply squaring the cumulative curve for single autotomy. Such a predicted curve has two properties that can be compared to the data: the mean of the distribution and its shape. The predicted line in Fig 2 visually conforms closely in both the average delay as well as the increased slope (i.e., decreased variability) of the cumulative molting data for double autotomy and is statistically consistent based on the Kolmogorov-Smirnov goodness of fit test $(\mathrm{P}>0.10)$. Whatever the signal that delays molting, the delay seems to be adequately described as an independent signal from each regenerating limb, rather than a joint effect of the combined bulk of the regenerates.

\section{The nature of the delay signal}

The injury-metabolism model predicts that the larger the structure to be regenerated, the longer the delay. Although this correlation is true for the two leg autotomy points, confirmed by previous experiments (O'Farrell and Stock, 1953), as well as ones performed above, it is not true for non-autotomy points nor for the structures other than

TABLE II

Variance of molting times for double vs. single-leg autotomized animals. The probability (P) of a chance reduction in variance due to a second autotomized limb is judged by an F-test, on pooled variances when appropriate.

\begin{tabular}{|c|c|c|c|c|c|c|}
\hline Species & Instar & Culture & $\underset{\mathbf{k}}{\text { Lutotomized, }}$ & $\begin{array}{c}\text { Culture } \\
\text { size, } \\
\text { n }\end{array}$ & $\underset{\mathbf{V}}{\text { Variance, }}$ & $\mathrm{F}=\underset{(P)}{=V_{1} / V_{2}}$ \\
\hline \multirow[t]{2}{*}{ Blattella germanica } & \multirow[t]{2}{*}{ IV } & $\begin{array}{l}\mathbf{A} \\
\mathbf{B} \\
\mathbf{C} \\
\mathbf{D}\end{array}$ & $\begin{array}{l}1 \\
1 \\
1 \\
1\end{array}$ & $\begin{array}{l}110 \\
110 \\
110 \\
110\end{array}$ & $\begin{array}{l}77.44 \\
61.78 \\
56.10 \\
66.16\end{array}$ & \multirow{2}{*}{$\begin{array}{r}1.265 \\
(<0.005)\end{array}$} \\
\hline & & $\begin{array}{l}\mathbf{A}^{\prime} \\
\mathbf{B}^{\prime} \\
\mathbf{C}^{\prime} \\
\mathbf{D}^{\prime}\end{array}$ & $\begin{array}{l}2 \\
2 \\
2 \\
2\end{array}$ & $\begin{array}{l}110 \\
110 \\
110 \\
110\end{array}$ & $\begin{array}{l}64.00 \\
48.44 \\
43.56 \\
50.69\end{array}$ & \\
\hline \multirow[t]{4}{*}{ Byrsotria fumigata } & \multirow[t]{2}{*}{ II } & A & 1 & 157 & 1217 & \multirow{2}{*}{$\left(\begin{array}{c}2.28 \\
(<0.0001)\end{array}\right.$} \\
\hline & & B & 2 & 175 & 533 & \\
\hline & \multirow[t]{2}{*}{ III } & C & 1 & 122 & 1038 & \multirow{2}{*}{$\begin{array}{r}1.408 \\
(<0.05)\end{array}$} \\
\hline & & D & 2 & 121 & 737 & \\
\hline
\end{tabular}




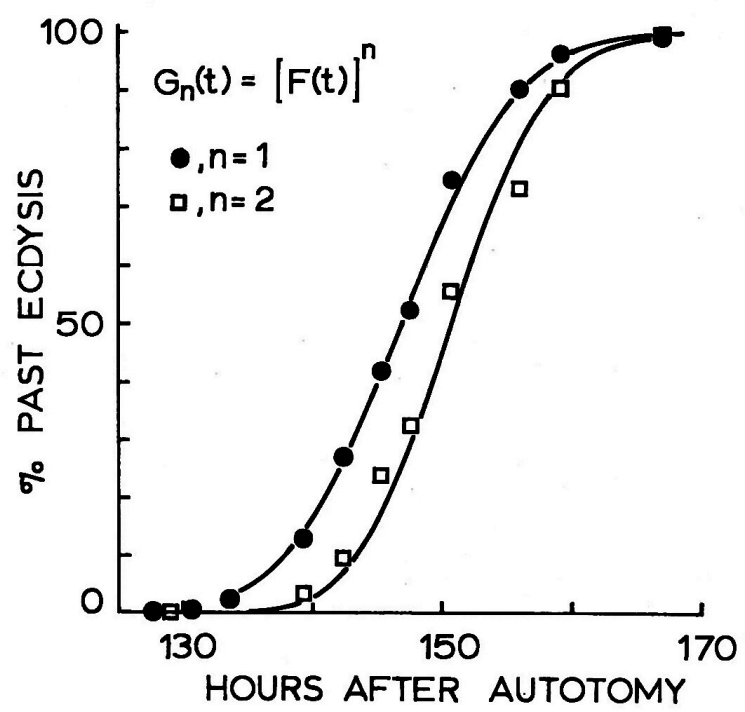

FIGURE 2. The effect of double vs. single autotomy on the ecdysis time in fourth instar $B$. germanica. In a culture of 104 +/or and 104 or/or larvae, the +/or larvae had 1 metathoracic femur-tibia-tarsus autotomized, while the or/or animals, had both metathoracic legs autotomized. A cumulative normal curve, $\mathrm{G}_{1}(\mathrm{t})=\mathrm{F}(\mathrm{t})$ was fit to the single-leg regenerate, $\mathrm{n}=1$, data and the square of the curve, $\mathrm{G}_{2}(\mathrm{t})=[\mathrm{F}(\mathrm{t})]^{2}$, was plotted as the prediction of when the double-leg regenerates, $\mathrm{n}=2$, should undergo ecdysis.

the walking legs of cockroaches. It has been recognized that amputation at nonautotomy points does not result in regenerates as large as does autotomy (Bulliere, 1967). The special nature of autotomy-induced delay is more clearly understood when the autotomy or amputation is performed close to the time of the critical-period-for-regeneration (Fig 3).

Six treatment groups served to contrast autotomy with amputation at nonautotomy points: an unamputated control group, a cercal amputated group, tarsal and femur-tibiatarsal autotomy groups, and tibial and coxal amputation groups. Unamputated controls showed a smooth sigmoid molting curve. Amputation of the cerci of the cockroach had no noticeable effect on the molting cycle length, and these results are not illustrated. About $15 \%$ of the tarsal and femur-tibia-tarsus autotomy groups had already passed the regeneration critical period at the time of autotomy and molted with the controls at the time they normally would have, without regenerating a limb; the remaining $85 \%$ of the animals of these autotomy groups delayed their molting cycle 25 or 55 hours, respectively, and regenerated the lost segments. Their cumulative molting curves are a composite of two sigmoid curves with a plateau in between. True amputations of limbs at non-autotomy points were performed using irridectomy scissors. Such groups of amputated animals did not conform to the previously described simple plateau and sizerelated delay of their cumulative molting curves. Amputation between the coxa and trochanter does not result in any regeneration at the subsequent molt. Some molting delay occurs which may be related to the substantial injury and blood loss caused by amputation at this non-autotomy point. Earlier amputation at the coxa (soon after the previous ecdysis) does result in enough time for limited regeneration from this non- 


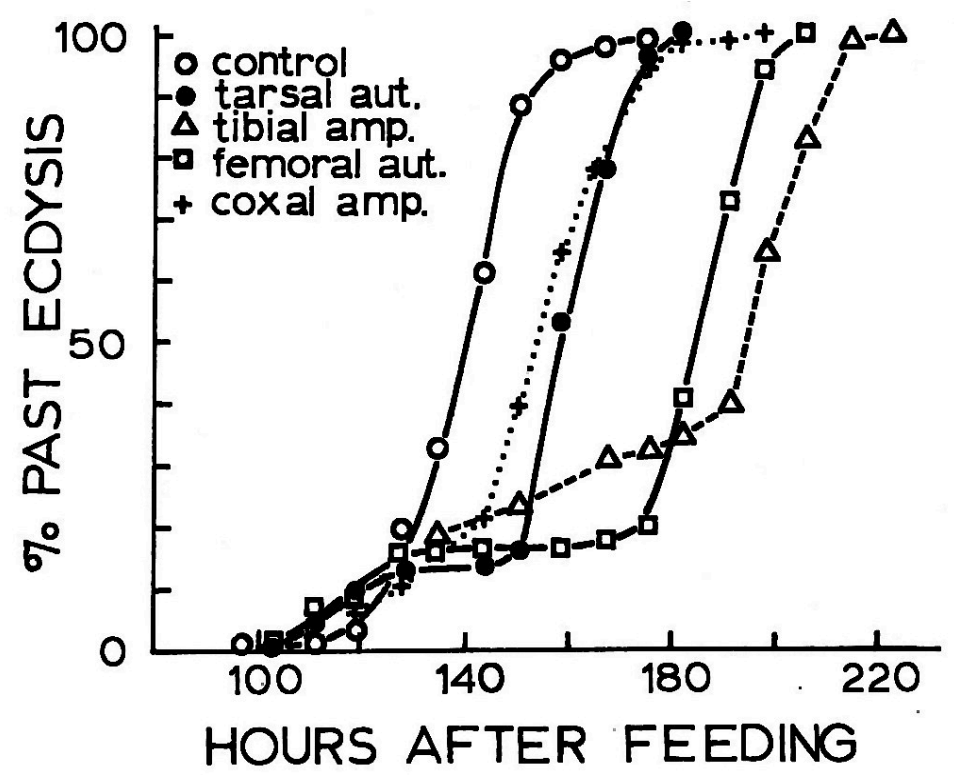

FIGURE. 3. Demonstration of the stereotypy of the molting delay signal. Groups of 81 fourth instar larvae of B. germanica were fed for 48 hours and then an appendage was autotomized or amputated at one of the indicated levels. The pattern of ecdysis for each group is contrasted to an unautotomized control group.

autotomy point. Amputation at the femur-tibial joint also had anomalous results. According to the "injury-metabolism" model, this group should have intermediate delay between the amount for tarsal autotomy and femur-tibia-tarsal autotomy. After an initial $15 \%$ of undelayed cockroaches molted in this group, the molting curve did not plateau but continued to rise slowly until about $30 \%$ had molted; the remaining $65 \%$ delayed their molting cycles longer than the femur-tibia-tarsus regenerates. It would seem from this experiment that the severity of the injury and the amount of prospective regeneration has little to do with the amount of delay of the molting cycle. Rather it seems that the integrity of the normal route of amputation (i.e., autotomy) is essential for signaling the need for an appropriate delay to allow for regeneration.

\section{Ganglion-leg communication and molting delay}

Attempts were made to demonstrate a nervous route of feedback from the autotomized limb to the brain. In these experiments the larger cockroach $P$. americana was used to facilitate the sectioning of nerves. Fig 4 summarizes an experiment in which information flow between the leg and its thoracic ganglion was interrupted. The four treatments were given to groups of seventh instar larvae at a time when approximately $10 \%$ of the animals had passed their critical period for regeneration.

The sham operates illustrate a normal molting cycle pattern. Autotomy resulted in a typical compound sigmoid curve with a plateau separating the undelayed nonregenerates from the delayed regenerates. Sectioning the nerves to an autotomized limb, just distal to their exit from the thoracic ganglion, eliminated the delay of molting as well as regeneration. Autotomy of an innervated contralateral leg restored the delay 


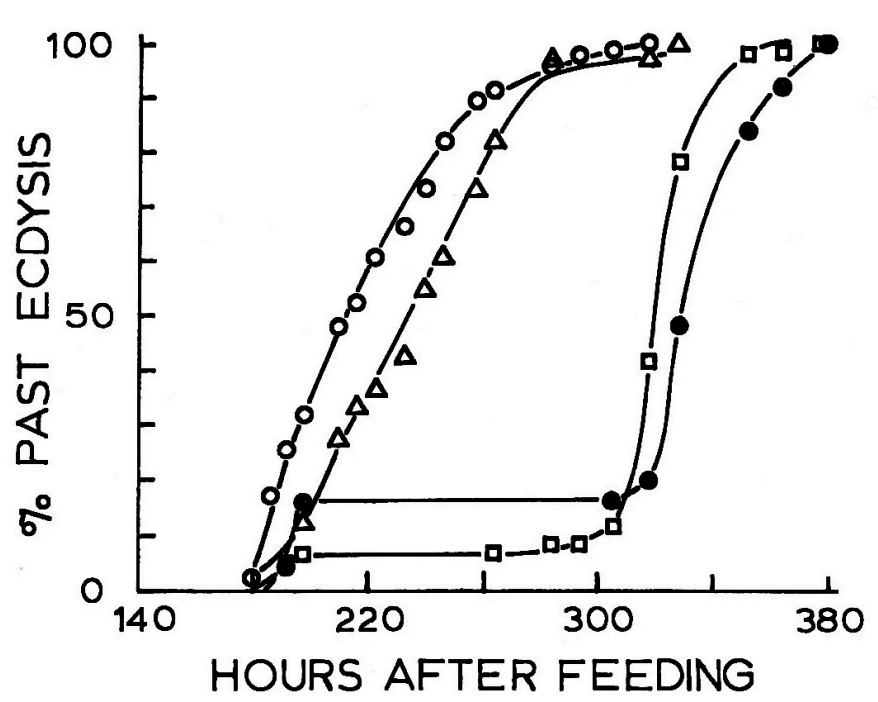

FIGURE 4. Effects of four sequentially more severe operations on cumulative molting curves of Periplaneta americana seventh instar larvae. The first group of 94 animals (open circle) had no leg autotomized but a sham surgical operation performed. A second group of 60 animals (square) had a limb autotomized and a sham operation also performed. The third group of 33 animals (triangle) had a limb autotomized and that leg's nerves cut. A fourth group of 25 (solid circle) had a limb autotomized, the leg nerves cut and a contralateral leg, with intact nerves, autotomized.. The two plateau levels are not significantly different from one another $(\mathrm{P}>0.10)$.

eliminated by nerve section. Of the 21 animals, of this latter group, which delayed their molting cycle to regenerate the contralateral-limb, four showed partial regeneration of the nerve-sectioned leg.

The failure of nerve-sectioned autotomized limbs to delay molting and regenerate is consistent with the nervous-feedback model. The proper sensory input from the limb stump is apparently essential to establish a delay. Since some nerve sectioned limbs did regenerate a leg, when given the proper delay time by autotomizing a contralateral limb, the ability to regenerate tissue could not in itself be sufficient to delay molting. It would seem that the connection of the stump in a formal fashion with its ganglion is essential for establishing a delay.

\section{Ganglion-brain communication and molting delay}

The ventral nerve cord between the meso- and metathoracic ganglion was chosen as a likely position to intercept information flow from a regenerating limb to the brain. Section of interganglionic connections would allow the thoracic ganglia to maintain their innervation of the legs, and therefore the centrifugal effect of nerves on regeneration would not be impaired. One complication, however, which arises in ventral nerve cord transected animals is that ecdysis cannot occur normally due to lack of coordination between the musculature anterior and posterior to the cord section. In order to bypass this difficulty, animals were assayed for regeneration by direct observation through the cuticle of the coxa (Penzlin, 1963). A culture of seventh instar Periplaneta nymphs was 
fed and the four treatments listed in Table III were administered at 84 hours after feeding, prior to the critical period for regeneration for most of the animals. Eight days after autotomy the coxae were scored for regeneration. Both mesothoracic and metathoracic autotomy groups show similar results; all animals regenerated their limb. Meso-metathoracic cord section of mesothoracic leg autotomized animals resulted in three nonregenerates even though this level of cord section should not have interfered with communication of the mesothoracic autotomy information to the brain. These animals should have delayed molting to regenerate as did the autotomy controls. The difference between the results of the cord-section controls and the pooled autotomy controls is significant by Fisher's exact test $(\mathrm{P}=0.02)$, which suggests that cord section itself increases the propensity to delay molting and regenerate. This unexpected difference among the controls may be due to injury associated with cord section or might be related to the normal initiation of molting which may require abdominal stretch receptor information input to the brain via the ventral nerve cord. Isolating the brain from a ganglion innervating an autotomized limb by cutting the interganglionic connectives dramatically reduces the proportion of regenerating limbs (treatment 4 vs. treatment 3; Fisher exact test, $\mathrm{P}<0.005$ ), suggesting that communication via the ventral nerve cord between the ganglion and the brain is important for molting delay.

\section{The relation of ecdysone pattern to regeneration}

In order to test whether regeneration is actually causing a delay of brain hormone release and subsequent ecdysone secretion, it would be necessary to know the titers of these hormones in individual cockroaches during the molting cycle. Although brain hormone titers are not as yet available, the development of radioimmune assays for ecdysone have made measurements of ecdysone titers in individual animals a reality (Bollenbacher et al., 1975).

In a preliminary experiment, $100 \mu 1$ samples of hemolymph were obtained from groups of fourth instar larvae in synchronous cultures of Blatta orientalis, and ecdysone was extracted from these samples. Both 5 and $50 \mathrm{ul}$ equivalents of the hemolymph extracts were assayed for ecdysone content. Ecdysone was reliably measured at each of the four chosen times during the cockroach molting cycle, using either the 5 or $50 \mathrm{ul}$ aliquots. This confirmed the adequacy of our assay technique and suggested that $5 \mathrm{ul}$ samples of hemolymph from individual animals could be used to estimate ecdysone titers in animals from synchronized cultures.

In the next experiment a large group of sixth instar Blatta orientalis nymphs were synchronized by feeding. Every 24 hours a $5 \mathrm{ul}$ sample of blood was taken from each of five randomly selected animals. At 98 hours half of the remaining animals had a metathoracic femur-tibia-tarsus autotomized, and samples were subsequently taken from both unautotomized controls and autotomized animals. Figure 5 demonstrates that, in the control non-regenerating animals, a peak of ecdvsone occurs in the later third of the molting cycle with the titer of ecdysone falling to low levels by the time of ecdysis. This is similar to earlier observations using the Calliphora bioassay for ecdysone in extracts of pooled whole B. germanica (Masner, Hangartner, and Suchy, 1975). The regenerating group shows a substantial delay in the peak of ecdysone parallel to the delay in molting. The five individual titers comprising each mean during the peak days of ecdysone titer in both groups show a substantial ecdysone concentration, suggesting 
that a broad peak of ecdysone titer occurs rather than transitory increases in a few individuals.

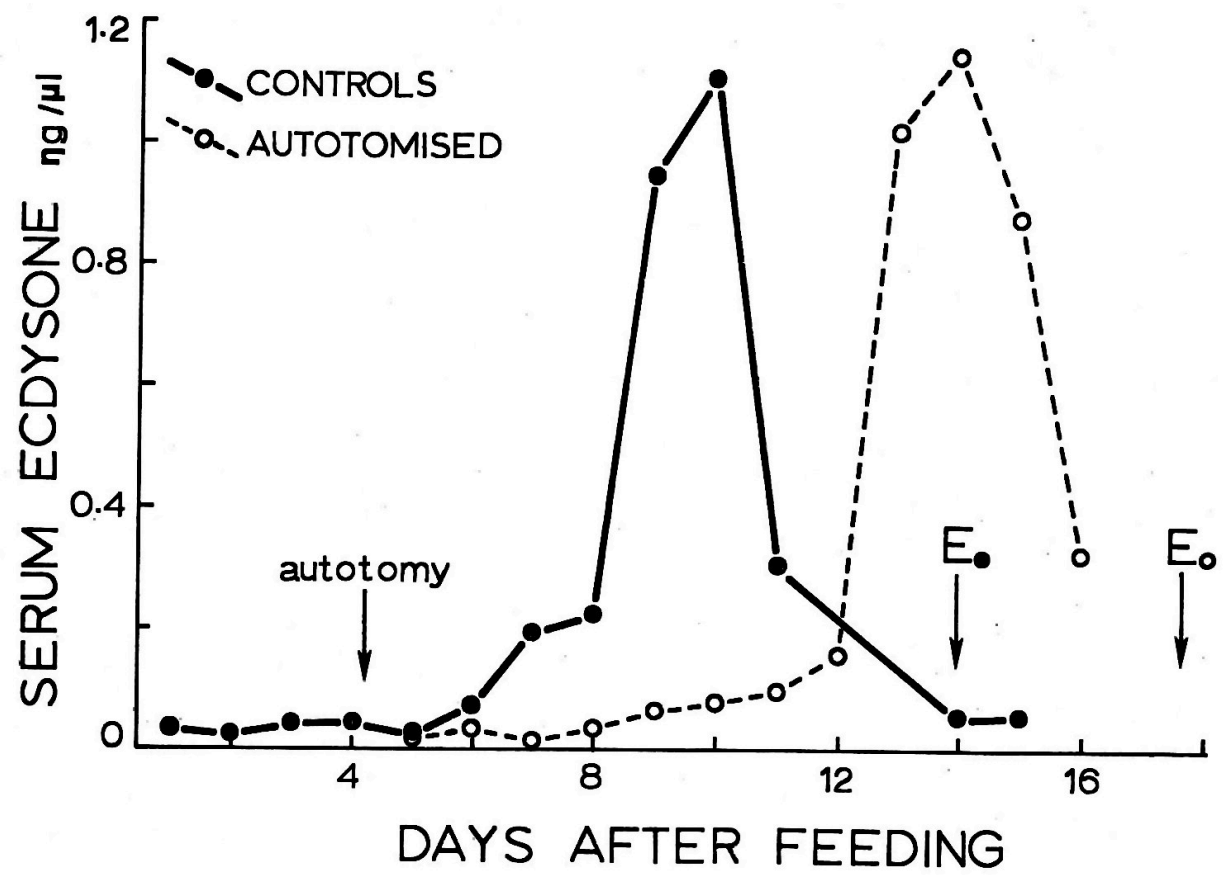

FIGURE 5. Serum ecdysone levels in normal and autotomized sixth instar larvae of Blatta orientalis. Autotomy of a metathoracic femur-tibia-tarsus was performed at the indicated time. A five microliter sample of hemolymph was taken from each of five animals randomly selected from mass synchronized cultures. ecdysone was measured on individual blood samples by radioimmune assay. The average ecdysone titer for each day is plotted for each group. The average times of

\section{Ecdysone titer and the regeneration critical period}

In order to clarify the relationship of the regeneration critical period to the increasing titer of ecdysone during the molting cycle, an experiment was designed in which the two phenomena were measured simultaneously in the same animals. Care was taken to estimate the limits of sensitivity of the radioimmune assay in order to establish whether any increase in ecdysone titer precedes the major rapid increase illustrated in the previous experiment. Males and females were analyzed separately, since they are known to differ in molting cycle length at this instar.

The data on regeneration critical period and individual ecdysone titer illustrated in Figure 6 can be read and interpreted in various ways. It should be noted that the midpoint of the males distribution of regeneration critical periods occurs about one day later than the females. 


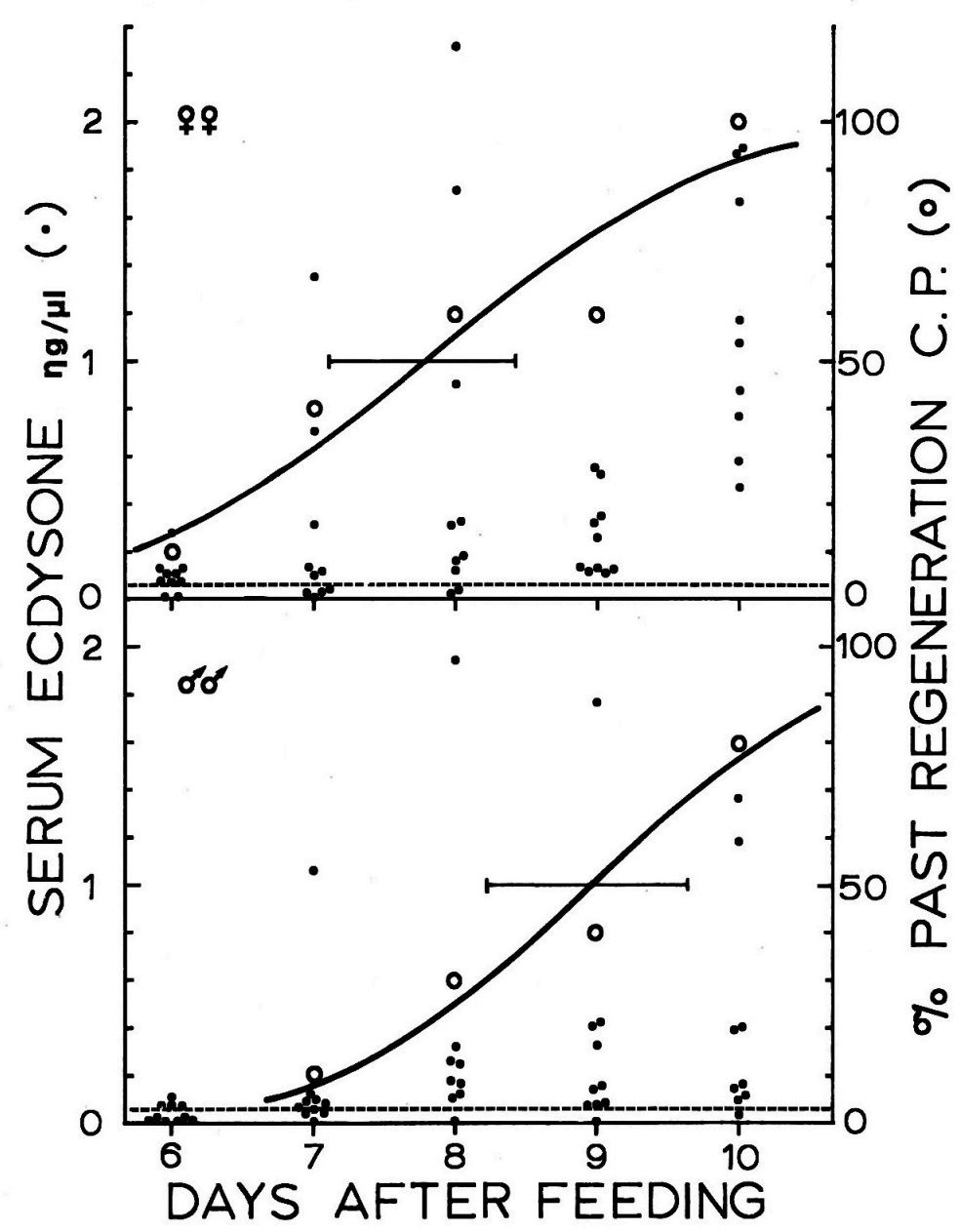

FIGURE 6. Simultaneous ecdysone titer and regeneration critical period determination for sixth instar larvae of Blatta orientalis. Twenty larvae, ten of each sex, were randomly selected from a large synchronized culture on days 6 through 10 after feeding. Each animal had a metathoracic femur-tibia-tarsus autotomized and a five microliter sample of hemolymph taken for ecdysone assay. Individual ecdysone titers (solid circles) and the proportion of animals which did not regenerate (open circles), are plotted against the time of autotomy and blood sampling. A cumulative normal curve was fitted to the proportions and used to calculate a 95 per cent confidence interval for the mean time of the regeneration critical period (horizontal bar). A 95 percent one sided confidence limit of the sensitivity of the ecdysone assay is indicated by the dashed line in each graph.

An increase in ecdysone titer seems to occur associated with passing the regeneration critical period. This is suggested by the fact that the proportion of animals with ecdysone titer greater than $0.25 \mathrm{ng}$ per microliter never exceeds the proportion of animals past the regeneration critical period. Also, the major peak of ecdysone titer in the females is just starting on day ten in this experiment, while already on days seven and eight there are 
TABLE III

Role of the ventral cord route between ganglion and brain in the autotomy-induced molting cycle delay and leg regeneration.

\begin{tabular}{l|c|c|c}
\hline \hline Treatment & $\begin{array}{c}\text { Number of } \\
\text { nonregenerates }\end{array}$ & $\begin{array}{c}\text { Number of } \\
\text { regenerateg }\end{array}$ & $\begin{array}{c}\text { Number } \\
\text { dying }\end{array}$ \\
\cline { 2 - 3 } 1. Mesothoracic autotomy control & 0 & 15 & 0 \\
2. Metathoracic autotomy control & 0 & 15 & 0 \\
3. Mesothoracic autotomy & 3 & 9 & 3 \\
$\quad$ + meso-meta cord section control & 11 & 2 & 2 \\
4. Metathoracic autotomy & & & \\
\hline
\end{tabular}

five of twenty animals with titers exceeding $0.6 \mathrm{ng}$ per microliter. These five animals are not likely to be outliers of the major ecdysone peak but more likely represent animals exhibiting a transitory increased ecdysone titer associated with passage of the regeneration critical period. Of course, the precise pattern of titer changes will remain moot until it is possible to follow an individual animal through the entire period of ecdysone titer change.

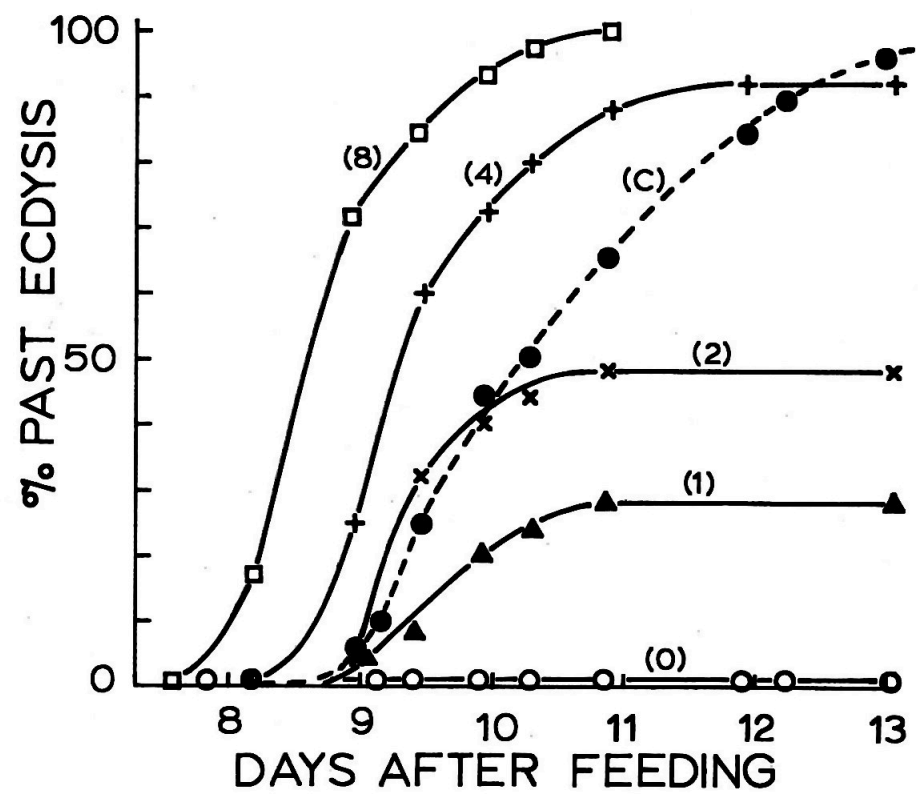

FIGURE 7. A graded response of cockroaches to eedysone. Graded doses of ecdysone (1, 2, 4, and $8 \mathrm{ug} /$ animal; triangle, $\mathrm{X}$, cross, square, respectively) were injected into groups of $25 \mathrm{limb}$ autotomized test animals. The cumulative percentage of each group which molted by a given time is plotted. In a control autotomized group injected with saline (open circle) 76 out of 77 had not molted by day 13. An unautotomized control group (solid circle) of 100 animals is included to show the normal time of molting. 
Ecdysone inhibits regeneration and molting delay when injected into autotomized cockroaches (Bulliere, 1972; Kunkel, 1975b). The timing of ecdysis due to exogenous ecdysone can vary considerably depending upon the dose. Fifth instar Blatta orientalis larvae had a metathoracic femur-tibia-tarsus autotomized 95 hours after feeding. The autotomized animals were randomized into six groups of 25 , and doses of ecdysone were administered. The response to ecdysone for each animal has an all or none component; that is, either an animal delays its molting cycle and regenerates a limb or it neither delays molting nor regenerates (Kunkel, 1975b). In addition, the animals which are prevented by the exogenous ecdysone from delaying their molting cycle to regenerate exhibit graded dose dependent responses to the injected ecdysone (Fig. 7). Below $1 \mathrm{ug} /$ animal, no animals showed any response to ecdysone. At the lower doses of 1 and $2 \mathrm{ug} /$ animal, the larvae which did not delay their molting cycles underwent ecdysis beginning at the same time as the unautotomized controls. At the higher doses, 4 and $8 \mathrm{ug} / \mathrm{animal}$, the larvae undergo ecdysis at successively earlier times, such that at the $8 \mathrm{ug} / \mathrm{animal}$ dose the median time of ecdysis is 1.6 days earlier than the unautotomized controls. This ability to accelerate the timing of ecdysis to different degrees is circumstantial evidence that the action of ecdysone is spread over a substantial time period in the individual cockroach. The low doses of ecdysone may have an effect comparable to the suggested early peak or rise of ecdysone which follows the brain critical period. The higher doses of ecdysone may be having an effect comparable to the major peak of endogenous ecdysone, bypassing or compressing the earlier events of the molting cycle, as has been described in the giant silk moth (Williams, 1968).

\section{DISCUSSION}

In the present study an attempt is made to clarify how limb regeneration in cockroaches causes a delay of the molting process. Evidence is presented which contradicts a previous "injury-metabolism model" and additional evidence is presented which supports a "nervous-feedback model" of molting delay.

The "injury-metabolism" model of molting delay was based on the results of a number of workers who observed correlations between the length of delay and the size of a regenerate (O'Farrell, Stock, Rae and Morgen, 1960; Pohley, 1965). Testing this model depended on deciding a direction of causality that underlies the observed correlation of size with delay-length. The experiments carried out above demonstrated that the amount of regenerating tissue could not be causing the length of the delay. Most likely there is an average delay time programmed for each type of autotomy in the hemiganglion serving a leg. This programmed delay was shown above not to depend on the size of the autotomized structure nor on the size of the resulting regenerate. That delay length is independent of the mass of the regenerating tissue is the major reason for rejecting the injury-metabolism model of molting delay. In lieu of the injury-metabolism model of delay and since the brain critical period had been mapped close to the time of the regeneration critical period (Kunkel, 1975a), it was hypothesized that the regenerate was in some way preventing brain hormone release. Consequently, routes of feedback to the brain were investigated. Despite the fact that innervation is not essential for regeneration to proceed if autotomy occurs early in a molting cycle (Penzlin, 1964), it 
was demonstrated above that the ganglion of the autotomized limb must be connected to the limb for proper delay of molting to occur, particularly when autotomy takes place when the regeneration critical period is imminent. Moreover, the ganglion of the autotomized limb must maintain its connection with the brain in order to establish the delay of molting. It is strongly suggested that the regenerating limb is delaying molting by preventing brain hormone secretion.

The nature of the source of the delay signal is subject to speculation. It may be that the sensory input from the limb is the source of information about the integrity of the leg. The pattern of leg movements in cockroaches is immediately responsive to autotomy of a limb (Delcomyn, 1971). Interestingly, like molting delay, walking pattern does not change when a leg is amputated at the femoral-tibial joint, a nonautotomy point. If the information on integrity of the locomotory system were able to be monitored by the brain, then a nervous route of control of brain hormone release would be a reasonable model for molting delay. If the limb were autotomized after the brain had released its ecdysiotropin, the animal would already be committed to molt and the resulting rising titer of ecdysone would shut off any regeneration that started. Thus, the all or none nature of regeneration in cockroaches is explained.

The length of the delay of molting was shown previously, as well as in the present study, to be specific for each type of regenerate and thoracic segment. The simplest explanation of the control of the length of delay is that it is determined by the hemiganglion serving each leg. It was shown above that the length of the delay associated with each regenerating limb is independent of each other regenerating limb. This suggests that there is an independent delay-determining process in the hemi-ganglion serving each leg. This might involve the neurons whose synthetic activities have been shown to be activated during regeneration (Cohen and Jacklet, 1965), or those which play an active part in the coxal muscle regression during limb regeneration (Shapiro, 1976). Differences in the neurons affected by tarsal and femur-tibia-tarsal autotomy could control the observed difference in delay due to level of autotomy.

The end of the delay associated with each leg and level of autotomy independently releases the brain from inhibition and when all autotomized limbs have stopped their delay signals, the brain promptly initiates a molting cycle. This ordered release from molting inhibition results in considerable increases in synchrony of molting cycles in the diverse selection of cockroach species examined. Although the additional increase in synchrony with multiple autotomy is in this instance a fortuitous phenomenon having little or no obvious functional value to the cockroach, the concept of poorly-timed phenomena combining in an ordered way to produce a more precisely-timed phenomenon is a valuable concept that could have applications to many areas. It is of practical use in working with cockroaches, because it can produce a culture of developing animals with substantially increased synchrony.

The end of the brain's delay in initiating molting must involve the final secretory release of ecdysiotropin, which has been demonstrated to stimulate the prothoracic glands to produce ecdysone (Gersh and Sturzebecker, 1970). However, the pattern of ecdysone secretion following the brain critical period is not simple. The major peak of eedysone in cockroaches occurs substantially after the regeneration critical period in the last third of the molting cycle. There is, however, evidence reported above that there is a low level or possibly a transitory high ecdysone titer that occurs about the time of the regeneration critical period. The timing of the major peak of ecdysone would place it approximately 
at the time of apolysis. The period of epidermal proliferation follows the brain critical period but precedes the major peak of ecdysone (Kunkel, 1965). Since the molting cycle becomes independent of the brain after the brain critical period, it would seem that the brain hormone stimulates the prothoracic glands to produce the early rise of ecdysone, and once this has occurred the rest of the events of the cycle occur independently of the brain. Part of the molting schedule, including epidermal proliferation, must be stimulated by low titers or early transitory increases of ecdysone and the rest of the molting schedule from apolysis on is controlled by the major ecdysone peak. A sequential action of ecdysone in controlling the molting cycle may be responsible for the observed differences in timing of molting seen when different doses of ecdysone were used to overcome the regeneration-induced delay of molting. This pattern of ecdysone titer in cockroaches is reminiscent of the two peaks of ecdysone seen during pupal development in the tobacco hornworm (Truman and Riddiford, 1974), but the pattern in cockroaches apparently does not require continuous modulation by the brain.

I am grateful to Professor Michael Locke for providing the stimulating atmosphere in which this research was initiated. The work was supported by grants from the National Institutes of Health, GM-09960 to M. Locke and GM-33259 and AI-11269 to J.G.K.

\section{SUMMARY}

1. The amount of regenerating limb tissue does not control the length of molting delay in cockroaches; rather, a programmed delay associated with each autotomy level and segment allows an appropriate delay for accomplishing the necessary regeneration.

2. Delay of molting is accomplished by inhibiting ecdysiotropin release.

3. Each regenerating limb produces a delay independent of other regenerating limbs.

4. Single and simultaneous double autotomies can be used to obtain substantially increased synchrony of the molting cycle of a wide variety of cockroach species.

5. The signal to delay molting is transmitted to the brain along the ventral nerve cord and requires the stereotyped sensory input associated with autotomy to initiate it.

6. There are two phases of ecdysone titer increase during the molting cycle of cockroaches. An early transitory or gradual increase is associated with the regeneration critical period, while a later major peak is associated with apolysis. The major ecdysone peak was shown to be delayed during leg regeneration.

\section{LITERATURE CITED}

BENSON, R. H., 1966. Limitations of tritium measurements by liquid scintilation counting. Anal. Chem., 38: 1353.

BOHN, H., 1965. Analyse der regenerations fahigkeit der insekten extremitat durch amputations und transplantationsversuche an larven der afrikanischen schabe Leucophaea maderae Fabr. (Blattaria). Wilhelm Roux' Arch. Entwicklungsmech. Org., 156: 49-74.

BOLLENBACHER, W. E., W. V. VEDECKIS, L. I. GILBERT, AND J. D. O'CONNOR, 1975. ecdysone titer and prothoracic gland activity during the larval-pupal development of Manduca sexta. Dev. Biol., 44: 46-53. 


\section{AUTOTOMY_INDUCED MOLTING DELAY}

BORST, D. W., AND J. D. O'CONNOR, 1974. Trace analysis by gas-liquid chromatography, radio immune assay and bioassay. Steriods, 24: 637-656.

BRINDLEY, H. H., 1897. On the regeneration of the legs in the Blattidae. Zool. Soc. Proc., 1897: 903-916.

BULLIERE, D., 1967. Etude de la regeneration chez un Insecte Blatopteroide, Blabera cranifer Burm. (Dictyoptere) 1. Influence du niveau de la section sur la regeneration d'une patte metathoracique. Bull. Soc. Zool. Fr., 92: 523-536.

BULLIERE, D., 1968a. Etude de la regeneration chez tin Insecte Blatopt6roide, Blabera cranifer Burm. (Dictyoptere). 11. Influence du moment de I'amputation dans l'intermue sur la regeneration de al patte metathoracique. Bull. Soc. Zool. Fr., 93: 69-82.

BULLIERE, D., 1968b. Etude de la regeneration chez un Insecte Blatopteroide, Blabera cranifer Burm. (Dictyoptere) III. Influence de la regeneration sur la duree du cycle d'intermue et le nombre de stades larvaires. Bull. Soc. Zool. Fr., 93: 215-257.

BULLIERE, D., 1972. Action de l'ecdysone et de l'inokosterone sur la regeneration d'appendice chez la larva de Blabera cranifer (Insect, Dictyoptere). C. R. Hebd. Seanc. Acad. Sci., 274: 1349-1352.

BULLIERE, D., AND F. BULLIERE, 1970. Regeneration et facteures endocriniens chez les insectes. C. R. Hcbd. Seanc. Acad. Sci., 271: 353-356.

BULLIERE, D., F. BULLIERE, AND P. SENGEL, 1969. Regeneration du tarse chez 1'embryon de Blabera cranifer (Insecte, Dictyoptera) en culture in vitro. C. R. Hebd. Seanc. Acad. Sci., 269: 355-357.

COHEN, M. J., AND J. W. Jacklet, 1965. Neurons of insects: RNA changes during injury and regeneration. Science, 148: 1237-1239.

DELCOMYN, F., 1971. The effect of limb amputation on locomotion in the cockroach, Periplaneta americana. J. Exp. Biol., 54: 453-472.

GERSH, M., AND J. STURZBECKER, 1970. Experimentelle stimulierung der Zellularen activtat der prothorakaldrusen von Periplaneta americana durch der aktivations faktor. J. Insect. Physiol., 16: 1813-1826.

HOLLAND, C. A., AND D. M. SKINNER, 1976. Interactions between molting and regeneration in the land crab. Biol. Bull., 150: 222-240.

KUNKEL, J. G., 1966. Development and availability of food in the German cockroach, Blattella germanica (L). J. Insect. Physiol., 12: 227-235.

KUNKEL, J. G., 1975a. Cockroach molting. I. Temporal organization of events during molting cycle of Blattella germanica (L). Biol. Bull., 148: 259-273.

KUNKEL, J. G., 1975b. Larval-specific protein in the order Dictyoptera-II. Antagonistic effects of ecdysone and regeneration on LSP concentration in the hemolymph of the oriental cockroach, Blatta orientalis. Comp. Biochem. Physiol., 51B: 177-180.

LARINK, O., 1975. On the development of scales in Lepisma sacharina L. (Insecta, Zygentoma). Verh. Dtsch. Zool. Ges., 1974: 205-208.

LUSCHER, M., 1948. The regeneration of legs in Rhodnius prolixus. J. Exp. Biol., 25: 334-343.

MARKS, E. P., 1973. Effects of beta-ecdysone on molt-linked differentiation in vitro. Biol. Bull., 145: 171-179.

MARKS, E. P., AND R. A. LEOPOLD, 1970. Cockroach leg regeneration, effects of ecdysterone in vitro. Science, 167: 61-62.

MASNER, P., W. HANGARTNER, AND M. SUCHY, 1975. Reduced titer of ecdysone following JH treatment in the German cockroach Blattella germanica. J. Insect Physiol., 21 : 17551762.

O'FARRELL, A. F., AND A. STOCK, 1953. Regeneration and the molting cycle in Blattella germanica L. I. Single regeneration in the first instar. Aust. J. Biol. Sci., 6: 485-500.

O'FARRELL, A. F., AND A. STOCK, 1954. Regeneration and the molting cycle in Blattella germanica L. III. Successive regeneration of both metathoracic legs. Aust. J. Biol. Sci., 7: 525-536. 
O'FARRELl, A. F., A. STOCK, C. A. RAE, AND J. A. MORGAN, 1960. Regeneration and development in the cockroach B. germanica. Acta. Soc. Entomol. Cech., 57: 317-324.

PENZLIN, H., 1963. Uber die regeneration bei schaben (Blattaria) I. Das regenerations vermogen und die genese des regenerats. Wilhelm Roux' Arch. Entwicklungsniech. Org., 154: 434465.

PENZLIN, H., 1964. Die bedentung des Nerven systems fur die regeneration bei der Insecten. Wilhelm Roux' Arch. Entwicklungsmech. Org., 155: 152-161.

PENZLIN, H., 1965. Die bedeutung von hormonen fur regeneration bei insekten. Zool. Jahrb. Allg. Zool. Physiol. Tiere, 71 : 584-594.

POHLEY, H-J., 1961. Interactions between the endocrine system and the developing tissue Ephestia kuhniella. Wilhelm Roux' Arch. Entwicklungsmech. Org., 153: 443-458.

POHLEY, H-J., 1965. Regeneration and the moulting cycle in Ephestia kuhniella. Pages 324-330 in V. Kiortis and H. A. L. Trampusch., Eds., Regeneration in animals. North Holland Pub. Co., Amsterdam.

ROHDENDORF, E. B., AND J. A. WATSON, 1969. The control of reproductive cycle in the female firebrat, Lepismodes inquilinus. J. Insect Physiol., 15: 2085-2101.

ROSS, M., AND D. G. COCHRAN, 1966. Genetic variability ill the German cockroach I. Additional genetic data and the establishment of tentative linkage groups. J. Hered., 57: 221-226.

SHAPIRO, E., 1976. Nerve-muscle interactions during limb regeneration in an insect. Ph.D. Dissertation, Yale University, New Haven, Connecticut, 177 pp. (Diss. Abstr., 37: 3225; order no. 76-29, 698.)

SHAW, V. K., AND P. J. BRYANT, 1974. Regeneration of appendages in the large milk weed bug, Oncopeltus fasciatus. J. Insect Physiol., 20: 1849-1857.

STOCK, A., AND A. F. O'FARRELL, 1954. Regeneration and the molting cycle in Blattella germanica L. II. Simultaneous regeneration of both metathoracic legs. Aust. J. Biol. Sci., 7: 302-307.

TRUMAN, J. W., AND L. M. RIDDIFORD, 1974. Physiology of insect rhythms III. The temporal organization of the endocrine events underlying pupation of the tobacco hornworm. J. Exp. Biol., 60: 371-382.

TYLER, J.P.P., J.F. HENNAN, J.R. NEWTON, AND W. P. COLLINS, 1973. Radioimmunoassay of plasma testosterone without chromatography. Steroids, 22: 871-889.

WILLIAMS, C. M., 1968. Ecdysone and ecdysone analogs: their assay and action on diapausing pupae of the cynthia silkworm. Biol. Bull. 134: 344-355. 